\title{
Inducible re-expression of pl6 in an orthotopic mouse model of pancreatic cancer inhibits lymphangiogenesis and lymphatic
} metastasis

\author{
P Schulz ${ }^{*, 1}$, A Scholz', A Rexin', P Hauff', M Schirner', B Wiedenmann' and K Detjen' \\ 'Department of Hepatology and Gastroenterology, Charité-Universitätsmedizin Berlin, Campus Virchow-Klinikum, Berlin I 3353, Germany; ${ }^{2}$ Global Drug \\ Discovery, Bayer Schering Pharma AG, Berlin 13342, Germany
}

Functional inactivation of the tumour suppressor protein $\mathrm{p} \mid 6^{\mathrm{INK} 4 \mathrm{a}}$ constitutes a key event in the multistep process of pancreatic ductal cell transformation. However, the significance of p 16 inactivation for complex and tissue-specific aspects of pancreatic cancer progression, such as angiogenesis and metastasis, is less understood. Here, we inducibly re-expressed pl 6 in vivo in an orthotopic model of pancreatic cancer and examined the impact on these clinically relevant aspects of pancreatic cancer tumour biology. Consistent with previous work in subcutaneous xenograft models, we found p 16 capable of reducing primary tumour growth. In addition, p 16 restitution resulted in a marked reduction of tumour angiogenesis, largely accounted for by a p I 6-dependent inhibition of lymphangiogenesis. In excellent agreement with the antilymphangiogenic effect, re-expression of p 6 almost completely prevented lymph node metastases of MiaPaca-2 pancreatic tumours. To our knowledge, this is the first report that experimentally links the tumour suppressor p 16 to the process of lymphangiogenesis.

British Journal of Cancer (2008) 99, I I0- | |7. doi: I0.1038/sj.bjc.6604457 www.bjcancer.com

Published online 24 June 2008

(C) 2008 Cancer Research UK

Keywords: pl $6^{\mathrm{INK} 4 \mathrm{a}}$; pancreatic cancer; orthotopic model; lymphangiogenesis; metastasis

At the time of diagnosis, most patients with pancreatic cancer require systemic therapy as invasive growth and metastatic spread occur early in the course of the disease (Hezel et al, 2006; Chu et al, 2007). Unfortunately, pancreatic cancer has proven remarkably resistant to current systemic treatment modalities including chemo- and radiotherapies (Xiong et al, 2006), suggesting a unique combination of molecular alterations accounts for this highly unfavourable biological profile. Several molecular alterations were identified, such that pancreatic cancer is now perceived as a genetic disease characterised by the sequence of oncogenic K-ras activation, inactivation of the tumour suppressor p $16^{\mathrm{INK} 4 \mathrm{a}}$, and inactivation of the tumour suppressors p53 and/or DPC4. Most pancreatic cancer cells harbour a combination of 3-4 of the alterations (Rozenblum et al, 1997). Activation of K-ras in virtually all samples of ductal pancreatic adenocarcinoma marks the initiation of the multistep transformation process, but functional inactivation of $\mathrm{p}^{\mathrm{INR} 4 \mathrm{a}}$ in up to $90 \%$ of cases ranks second in frequency (Caldas et al, 1994; Hezel et al, 2006).

p16 was discovered as a tumour suppressor and an inhibitor of cyclin D-associated CDK complexes. The main biological function

\footnotetext{
*Correspondence: Dr P Schulz, Med. Klinik m.S. Hepatologie u. Gastroenterologie, Charité-Universitätsmedizin Berlin, Campus VirchowKlinikum, Augustenburger Platz I, D- 13353 Berlin, Germany;

E-mail: petra.schulz@charite.de

Dedicated to Professor Stefan Rosewicz (1960-2004) who contributed significantly to this work.

Revised 7 May 2008; accepted 12 May 2008; published online 24 June 2008
}

of $\mathrm{p} 16^{\mathrm{INK} 4 \mathrm{a}}$ indeed involves the regulation of cell cycle progression at the G1/S boundary (Serrano et al, 1993). Additional biological functions in processes such as cell senescence, invasive growth, cell spreading, apoptosis, anoikis and angiogenesis were subsequently reported. p16 $6^{\mathrm{INK} 4 \mathrm{a}}$-deficient mice present with increased incidence of spontaneous and carcinogen-induced cancers (Kim and Sharpless, 2006). More recently $\mathrm{p} 16^{\mathrm{INK} 4 \mathrm{a}}$ was associated with the clonal evolution of epidermal cells such that inactivation of p16 maintained epidermal cells in the stem cell compartment (Maurelli et al, 2006). In extension of these findings, knockout models have unveiled an age-dependent, tissue-specific function of p16 in limiting stem cell renewal (Kim and Sharpless, 2006).

A central role of p16 in pancreatic carcinogenesis was firmly established from the analysis of clinical specimens and corroborated by subsequent genetic studies in mice, as tissue-specific oncogenic activation of $\mathrm{K}$-ras in Ink4a/ARF ${ }^{-1-}$ or Ink $4 \mathrm{~A}^{-1-} / \mathrm{ARF}{ }^{+1+}$ mice, but not in wild-type mice resulted in pancreatic ductal adenocarcinoma (Aguirre et al, 2003; Bardeesy et $a l, 2006)$. Also, tumour formation in the pancreas of $\mathrm{p} 53^{-1}$ mice overexpressing TGF- $\alpha$ was accompanied by deletion of the INK4a locus (Wagner et al, 2001). Owing to the tumour suppressor function, p16 reconstitution represents an appealing therapeutic approach. Accordingly, the biological effects following reconstituting p16 function in vitro have been extensively characterised (Rocco and Sidransky, 2001) and p16 was shown to inhibit growth of subcutaneous xenografts (Spillare et al, 1996; Rocco et al, 1998). However, little is known about the consequences of p16 re-expression for more complex aspects of tumour biology such as vascularisation and metastatic spread. 
This may reflect on the experimental limitations of the subcutaneous approach, which fails to provide a representative microenvironment (Killion et al, 1998). Therefore, we aimed to study the effects of p16 in the more physiologic microenvironment of an orthotopic xenograft model. We furthermore, were concerned about epigenetic changes that might accompany the selection of clones with stable overexpression of p16. Therefore, an inducible expression system seemed mandatory.

In consequence, we combined an inducible expression system in pancreatic cancer cells with an orthotopic tumour model to study the effects of p16 reconstitution on tumour formation, growth, invasion, angiogenesis and metastasis in a representative in vivo model.

\section{MATERIALS AND METHODS}

\section{Cell culture}

MiaPaCa-2 cells (ATCC, Manassas, VA, USA) were grown as subconfluent monolayers in DMEM (Invitrogen, Berlin, Germany) containing $10 \%$ FCS, $2 \mathrm{mmoll}^{-1}$ glutamine and $100 \mathrm{U} \mathrm{ml}^{-1}$ penicillin/streptomycin (Biochrom, Berlin, Germany) at $37^{\circ} \mathrm{C}$ in $95 \%$ air and $5 \% \mathrm{CO}_{2}$.

\section{Cloning and generation of the tetracycline inducible cell line MiaPaCa-2-TREx-p16}

The components of the TREx system (Invitrogen, Berlin, Germany) include the regulatory plasmid ( $p c D N A 6 / T R$ ), the inducible plasmid (pcDNA4/TO) and a luciferase encoding reporter plasmid (pcDNA4/TO-Luc). MiaPaCa-2 cells were transfected (Effectene, Quiagen, Hilden, Germany) with pcDNA6/TR and stable clones (MiaPaCa-2-TREx) were selected by blasticidin $\left(5 \mu \mathrm{g} \mathrm{ml}^{-1}\right)$. TetR promoter activation was achieved with $1 \mu \mathrm{g} \mathrm{ml}^{-1}$ Doxycycline (Sigma Chemical Co., Deisenhofen, Germany) and responsiveness was evaluated by transient transfection with pcDNA4/TO-Luc followed by a luciferase assay (Promega, Mannheim, Germany). The full length cDNA of p16 was subcloned into pcDNA4/TO using restriction enzymes HindIII and KpnI (Invitrogen, Berlin, Germany), resulting in pcDNA4/TO-p16. MiaPaCa-2-TREx-p16 cells were obtained through transfection of pcDNA4/TO-p16 into the MiaPaCa-2-TREx cells and selection with zeozin $\left(0.5 \mathrm{mg} \mathrm{ml}^{-1}\right) /$ blasticidin $\left(5 \mu \mathrm{g} \mathrm{ml}^{-1}\right)$ (Invitrogen, Berlin, Germany).

\section{Western blotting}

Cell lysates were prepared and blotted as described (Plath et al, 2000). Membranes were blocked and reacted overnight at $4{ }^{\circ} \mathrm{C}$ with monoclonal antibodies (anti-p16 ${ }^{\mathrm{INK} 4 \mathrm{a}}(1: 1000)$ BD Pharmingen, Heidelberg, Germany), anti-pRB (1:1000) BD Pharmingen), antiVEGF-C (Zytomed, Berlin, Germany) or VEGF-D (von Marschall et al, 2005), followed by appropriate secondary antibodies. Immunoreactive bands were visualised using an enhanced luminol reagent (Perkin-Elmer Life Science, Boston, USA).

\section{Cell proliferation (AlamarBlue assay)}

Alamar Blue dye was purchased from Biosource International Inc. (Camarillo, CA, USA) and the manufacturer's instructions were followed to complete the assay (Ahmed et al, 1994; Nakayama et al, 1997).

\section{Anchorage-independent growth}

For evaluation of anchorage-independent growth, $10^{3}$ cells were diluted in $1 \mathrm{ml}$ methylcellulose/agar mixture resolved in Iscove's medium (Invitrogen, Berlin, Germany) supplemented with $27 \%$ fetal bovine serum (HyClone, Utah, USA). Cells were plated in triplicate on $3-\mathrm{cm}$ dishes and incubated for 10 days. Colonies containing $>20$ cells were counted with an inverted light microscope.

\section{Animals}

Female NMRI nude mice were purchased from Taconic M\&B, Denmark. The studies were performed in accordance with a protocol approved by the regional animal research committee the 'Landesamt für Gesundheit und Soziales Berlin Nr. A0136/01'. The in vivo procedures were in compliance with the UKCCCR guidelines.

\section{Orthotopic implantation}

Orthotopic implantation was carried out when mice were about 7-8 weeks old. General anaesthesia was performed by intraperitoneal injection of a mixture of ketamine $\left(100 \mathrm{mg} \mathrm{kg}^{-1}\right)$ and xylazine $\left(20 \mathrm{mg} \mathrm{kg}^{-1}\right)$. In $2 \times 12$ animals, $1 \times 10^{6}$ MiaPacaTREx-p16 cells were injected into the head of the pancreas to visibly infiltrate the pancreatic tissue (Alves et al, 2001). In two mice the implantation failed due to a loss of cells into the abdomen during the procedure. Therefore the mice have to be killed. In successful implanted animals $(n=22)$ p16 induction was started one day after tumour cell inoculation by adding doxycycline $\left(2 \mathrm{mg} \mathrm{m}^{-1}\right)$ plus $2 \%$ sucrose to the drinking water $(n=11$ mice), whereas control animals received $2 \%$ sucrose alone $(n=11$ mice). All animals tolerated the procedure well. After implantation, mice were inspected daily for body weight loss, general condition, and tumour formation in the peritoneal cavity (abdominal distension). At the time of killing, primary tumours were removed and weighted. Tumour volume was calculated using the formula length $\times$ width $\times$ depth $\times \pi / 6$. Mesenterial and liver hilus lymph nodes were routinely collected for further examination.

\section{Immunohistochemistry}

Primary tumours and lymph nodes were analysed by standard immunoperoxidase staining procedure. Briefly, $7 \mu \mathrm{m}$ thick cryosections were fixed in $4 \%$ paraformaldehyde/PBS, $\mathrm{pH} 7.0$, for $20 \mathrm{~min}$ at room temperature (RT), treated with $0.3 \% \mathrm{H}_{2} \mathrm{O}_{2}$ for $10 \mathrm{~min}$ and incubated overnight at $4{ }^{\circ} \mathrm{C}$ with anti-human p16 ${ }^{\text {INK4a }}$ (NEOMarkers, CA, USA) or $1 \mathrm{~h}$ at RT with antibodies to mouse LYVE-1 (Relia Tech, Braunschweig, Germany), mouse CD31 (BD Pharmingen, Heidelberg, Germany) or human pancytokeratin-HRP (Santa Cruz Biotechnology, CA, USA) (1:50) followed by incubation with a biotinylated secondary antibody. Immunoreactivity was detected with an avidin-biotin complex method (Vectastain Elite ABC kit) and AEC substrate. Sections were counterstained with hematoxylin.

\section{Angiogenesis and lymphangiogenesis}

For quantitation of microvessel density (MVD) and lymphatic vessel density, respectively, the average numbers of CD31 and LYVE-1 positive vessels from three areas of maximal vascular density (vascular hotspots) were counted (Weidner, 1995).

\section{Statistical analysis}

Data were analysed by $t$-test and Fishers exact test using Graph Pad statistical software (GraphPad Software Inc., San diego, CA, USA). Differences were considered significant at $P<0.05$. 


\section{RESULTS}

\section{Generation of MiaPaCa-2 pancreatic cancer cells with} doxycycline-inducible expression of p16

To obtain inducible p16-expression in pancreatic cancer cells in vivo, a modified tetracycline-inducible expression system (Gossen et al, 1995; Yao et al, 1998) was chosen, which permits in vivo gene induction by adding tetracycline to the drinking water.

Initially, we established MiaPaCa-2 cells with stable integration of pcDNA6/TR, which encodes the tet-repressor. Clones with abundant expression were subsequently identified in transient cotransfections with a tet-repressor-regulated luciferase reporter construct (data not shown). A clone with approximately 10-fold induction (clone MiaPaCa-TREx-10) was identified and utilised in a second transfection to introduce pcDNA4/TO-p16, which encodes p16 under the control of a tet-responsive promoter, such that tetracycline or doxycycline induce p16 expression. Western Blot analysis of multiple independent stable transfected clones revealed variable responses to doxycycline, ranging from no effect (clone number 11) to high expression of p16 associated with varying degrees of promoter leakage (Figure 1A, clone 13,14). We chose two clones (number 13 and 16, not shown) for further studies, as these clones provided pronounced induction of p16 expression with minimal 'leakage' of basal p16 expression in the absence of doxycycline. The latter was of particular importance to ascertain that cells maintained the characteristics of parental MiaPaca-2 cells under control conditions. More detailed analyses revealed that p16-induction was rapid in onset, resulting in substantial amount of p16 at $24 \mathrm{~h}$ followed by a modest further increase up to $96 \mathrm{~h}$. These analyses also confirmed the negligible background expression in the absence of Dox treatment.

Because p16 has been shown to suppress pRB expression in vitro, we hypothesised that $\mathrm{pRB}$ expression could provide a simple indicator for the functional integrity of the p16 molecule expressed from the Dox-regulated vector system. Indeed, induction of p16 in MiaPaCa-2 TREx-p16 cells reduced pRB content,
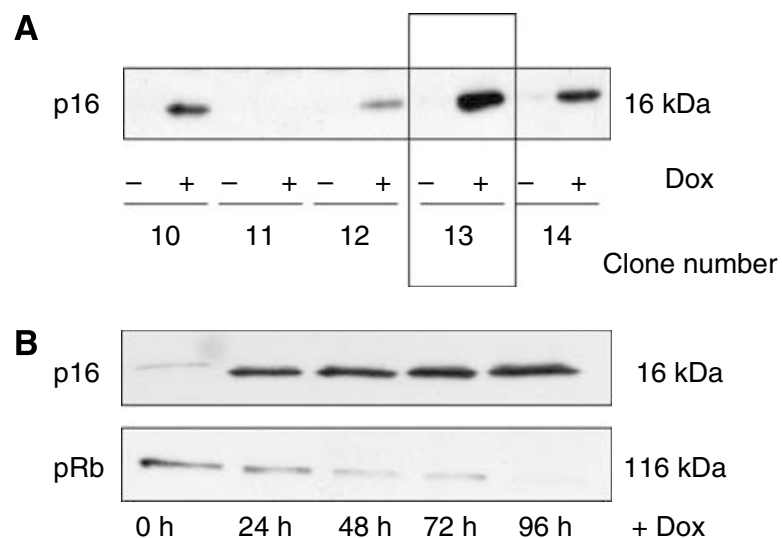

Figure I Generation MiaPaCa-2-TREx-p/6 cells with doxycyclininducible expression of pl6. (A) The plasmids pcDNA6/TR and pcDNA4/TO-p I 6 were sequentially transfected into p I6-deficient MiaPaCa-2 cells and clones with inducible expression of p 16 were selected (MiaPaca-2-TREx-p I6). For each of the zeozine-resistant MiaPaCa-2-TRExpl 6 clone, cells were grown for $48 \mathrm{~h}$ in the presence (+Dox) or absence (-Dox) of $1 \mu \mathrm{g} \mathrm{ml}^{-1}$ doxycycline. The expression of $\mathrm{p} / 6$ protein was analysed by western blotting. The clones with the highest p 16 induction and lowest basal expression were further analysed, for example clone 13. (B) Time course of doxycycline-induced pl6 expression. Cells were cultured for $96 \mathrm{~h}$ in the presence or absence of doxycycline and each $24 \mathrm{~h}$, lysates were prepared for western blot analysis of pl6 (upper panel) and pRB (lower panel). Equal amounts of protein $(20 \mu \mathrm{g})$ were separated on sodium dodecyl sulphate polyacrylamide gel electrophoresis. indicating that a functionally intact p16 molecule was induced (Figure 1B).

\section{Effects of doxycycline-induced p16 expression on growth of MiaPaCa-2-TREx cells in vitro}

Effects of p16 on proliferation of MiaPaCa-2 cells in vitro were studied next. A time-dependent increase in cell numbers was observed both in the presence and absence of Dox. Although a trend towards a reduction of cell numbers was observed in Dox-treated cultures, this effect did not reach statistical significance (Figure 2A).

In our previous studies, p16 restitution in Capan-1 cells abrogated tumorigenicity in vivo (Plath et al, 2000), which was reflected by a severe reduction of colony formation in vitro. We therefore examined the impact of p16 induction on colony formation of MiaPaCa-2 cells and observed a $\sim 30 \%$ decrease following addition of Dox (Figure 2B). Comparable results were obtained with MiaPaCa-2-TREx-p16 clone no. 16 (data not shown).

Taken together, inducible p16 expression elicited minor direct growth inhibitory effects on MiaPaCa-2 cells in vitro. Thus, this cell model seemed ideally suited to provide information about the context driven effects of p16 on tumour growth.

\section{Induction of p16 inhibits primary tumour growth of orthotopic MiaPaCa-2 xenografts}

As we intended to study the inducible MiaPaCa-2-TREx-p16 cell system in the orthotopic context, we initially had to confirm the
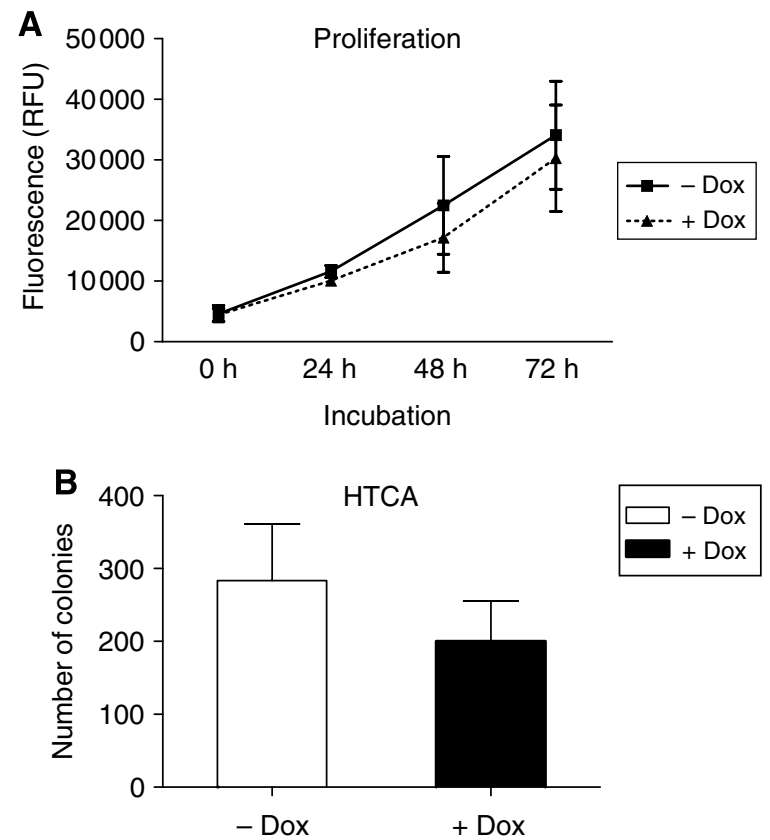

Figure 2 Effects of doxycycline-induced $\mathrm{p} / 6$ expression on growth of MiaPaCa-2-TREx cells in vitro. (A) Time-dependent proliferation of MiaPaCa-2-TREx-p/6 cells in the presence and absence of Dox as determined based on Alamar Blue assay. Every $24 \mathrm{~h}$ alamar blue dye was applied to the media of the cells and fluorescence was determined as an indirect measurement of cell numbers. (B) Effects of p 16 expression on anchorage-independent growth of MiaPaCa-2-TREx-p/6/13 cells. Anchorage-independent growth was evaluated based on soft agar colony formation. $10^{3}$ cells were seeded out in a methylcellulose/agar mixture and incubated in the presence (+Dox) or absence (-Dox) of doxycycline for 10 days. Vital colonies were counted. Values shown are the mean \pm s.e.m. for each group $(+/-$ Dox $)$ of three independent experiments. 
feasibility of this approach. Indeed, MiaPaca-2-TREx gave rise to extensive local tumour growth with invasion of adjacent organs exactly as parental MiaPaca-2 cells. Furthermore, Dox treatment of mice carrying MiaPaca-2-TREx cells was well tolerated and did not significantly reduce primary tumour weight, suggesting that Dox treatment per se would not confound growth regulatory effects of p16 induction (data not shown).

We then proceeded to induce p16 expression in tumour bearing mice as described in material and methods. After 8 weeks mice were killed and primary tumours were removed to determine volume and weight. Representative pictures of the abdominal situs in mice from control ( - Dox) and treatment groups ( + Dox $)$ at the time of autopsy are presented in Figure 3A. Mean tumour weight and volume of primary tumours were lower in treated animals, but a conspicuous variation of values in the treatment group precluded statistical significance. We hypothesised that this variability might reflect differences in the level of p16 induction and accordingly examined p16 expression by immunohistochemistry. Successful in vivo induction was evident in 6 out of 11 mice with MiaPaCa-2TREx-p16 orthotopic tumours (Figure 3B). p16 was absent in 8 out of 11 mice from the control group, but a weak signal was obtained in the remaining three control tumours, possibly due to promoter leakage. Based on these results, we excluded tumours of animals without immunohistological corroboration of p16 expression or absence from the analysis. When weight and volume from the tumours with confirmed re-expression of p16 were compared to values from controls, a significant reduction by 60 and $52 \%$, respectively, was noted (Figure $3 \mathrm{C}$ ). Furthermore, several control tumours, but none with p16 induction invaded into surrounding tissues as stomach and duodenum (data not shown). Altogether, re-expression of p16 in pancreatic cancer cells substantially reduced orthotopic tumour growth in vivo and thus surpassed the growth inhibitory effects in vitro.

\section{Induction of p16 expression reduced angiogenesis in orthotopic MiaPaCa-2 pancreatic carcinoma}

Growth inhibition may have resulted from direct antiproliferative or proapoptotic effects of p16 in the tumour cells or from indirect mechanisms. As vascularisation is a prerequisite for tumour growth, we examined whether p16 affected angiogenesis. Cryosections of the primary tumours were stained with CD31 (Figure 4A) to detect endothelial cells and average MVD was determined. MVD values in the control group ranged from 38 to
A

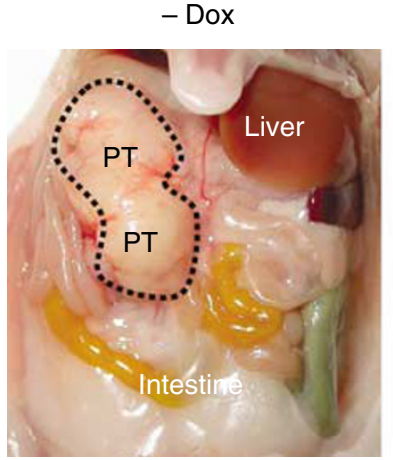

B
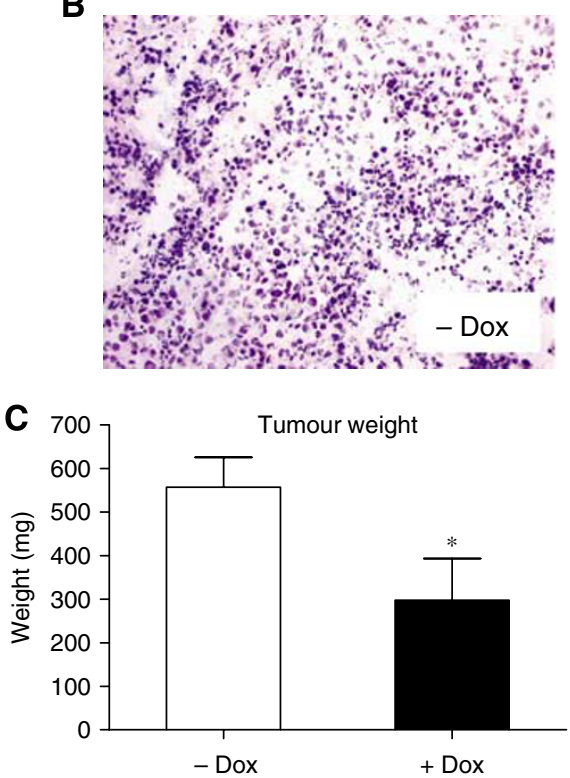

+ Dox
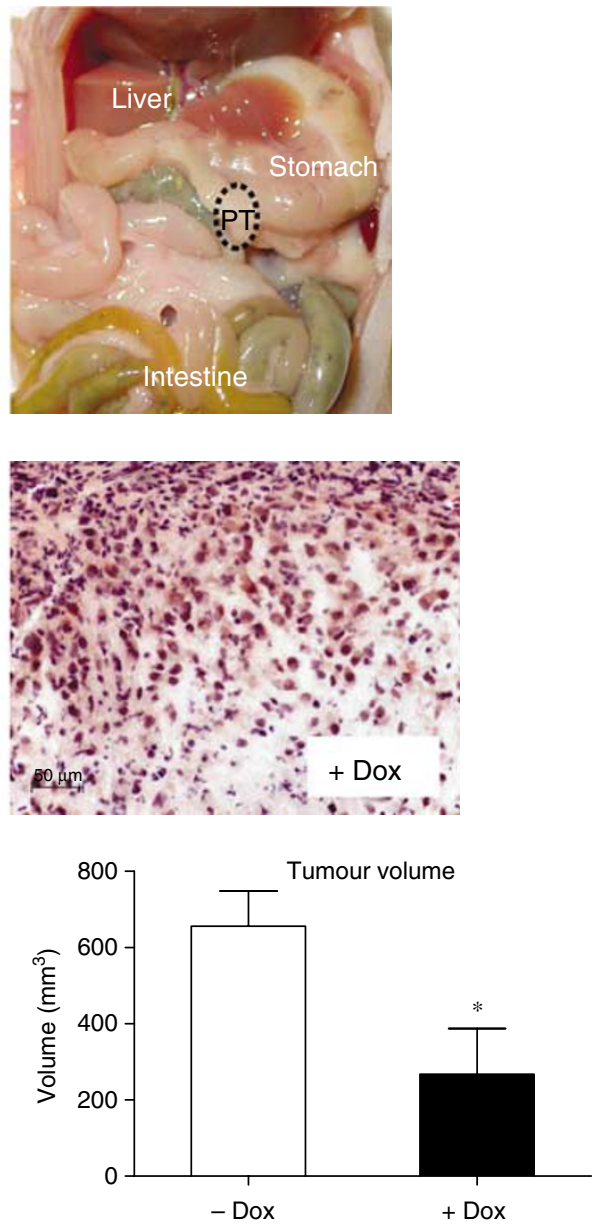

Figure 3 Induction of p 16 expression reduced primary tumour growth in orthotopic MiaPaCa-2 pancreatic carcinomas. Pancreatic MiaPaCa-2-TREx-p I 6 cells were grown orthotopically in the pancreas of mice treated with or without Dox as indicated. At the end of the treatment (8 weeks) tumour volumes and weights were calculated. (A) Open situ of representative mice from the control (-Dox) and treatment group (+Dox). (B) Confirmation of pl6 induction in vivo. Primary tumours were analysed for p 16 expression by immunohistochemistry using an antibody against p 16 . An example of p 16 expression in a small tumour in the treatment group is shown on the right panel, with detection of p 16 protein in the nucleus and in the cytoplasm of tumour cells. In contrast, no signal was obtained in control tumours (-Dox) (images at $\times 20$ magnification). (C) Summary of primary tumour weights (left) and volumes (right) from Dox-treated animals. Data represent mean \pm s.e.m. for each group. $* P<0.05$. 


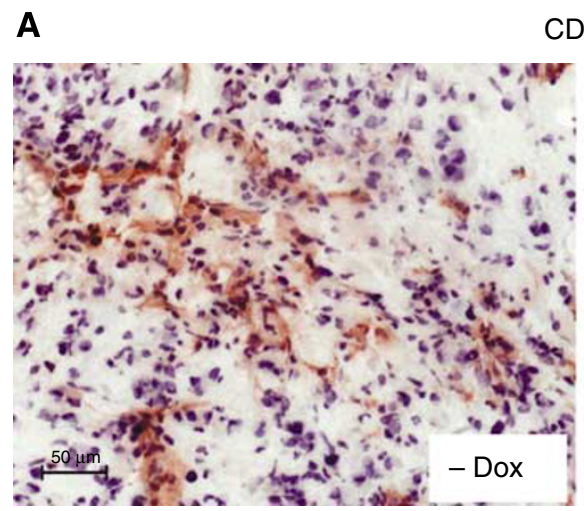

CD31-IHC
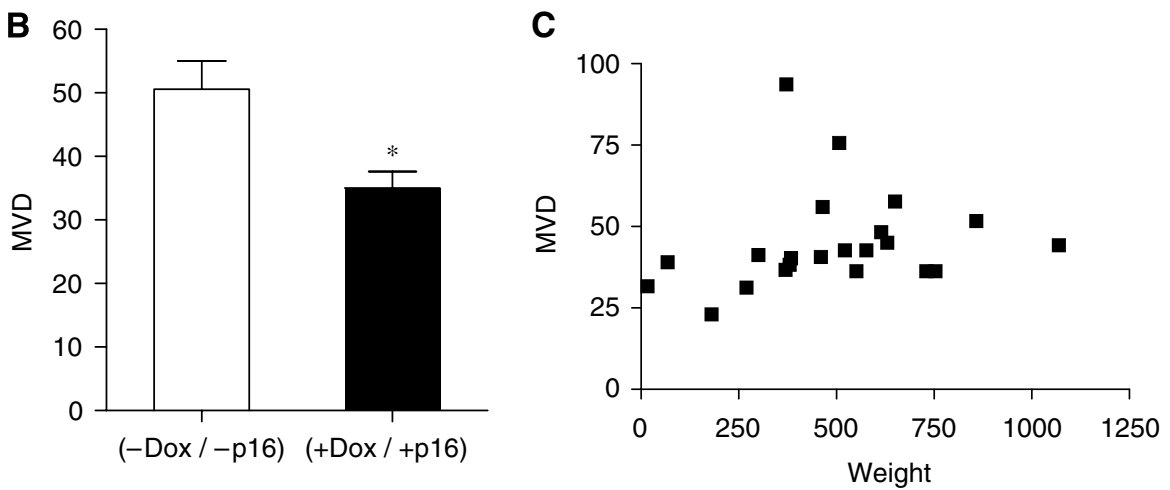

Figure 4 Induction of p 16 expression reduced angiogenesis in orthotopic MiaPaCa-2 pancreatic carcinomas. Cryosections of the tumours from control (-Dox) and treatment group (+ Dox) were stained with the endothelial marker CD31. To determine microvessel density (MVD) CD3I-expressing vessels were quantitated from hotspot areas, as described in Materials and methods. (A) Shown are representative CD3I stainings from a ( - Dox) and a (+ Dox) tumour $(\mathbf{B})$ and quantitative evaluation of the results, ${ }^{*} P<0.05$. (images at $\times 20$ magnification) (C) Relationship of MVD and tumour weight. MVD values from both groups ( + /-Dox) were plotted against the respective tumour weight to assess a potential correlation of both parameters. The distribution shows no correlation.

76, indicating that the MiaPaca-2 tumours were well vascularised. Induction of p16 significantly reduced the MVD (35 vs 51, $P=0.0123$, Figure 4B). It is noteworthy that tumour size per se did not correlate with MVD (Figure 4C), indicating that reduced MVD observed in the treatment group likely reflected a specific biological effect of p16 restitution.

\section{Induction of p16 expression reduced lymphangiogenesis in orthotopic MiaPaCa-2 pancreatic carcinoma}

Owing to the reduction in MVD apparent from CD 31 staining could result from an inhibition of either hem- or lymphangiogenesis, the latter was separately determined based on the immunostaining with LYVE-1 (Figure 5A), an antibody that recognises the hyaloronan receptor-1 of lymphatic vessels. Tumours with confirmed p16 induction ( + Dox) contained less Lyve-1 positive lymphatic vessels than control tumours $(33 \%$ reduction, $P=0.0299$, Figure 5B). Similar to MVD, LVD did not correlate with tumour size (Figure 5C). Thus, re-expression of p16 inhibited lymphangiogenesis.

\section{Induction of p16 expression reduced metastasis in orthotopic MiaPaCa-2 pancreatic carcinoma}

As tumour size, tumour angiogenesis and lymphangiogenesis are important determinants of metastatic tumour progression, metastasis formation of orthotopic MiaPaCa-2 tumours was examined. On macroscopic inspection the abdominal organs and lungs of either treatment or control group were tumour-free. At the microscopic level however (Figure 6A), human MiaPaCa-2-TREx-p16 cells were detected in liver hilus lymph nodes of 10 out of 11 mice in the control group (91\%), using an anti-human pan-cytokeratin antibody (Figure 6A and B). In contrast, hilar lymph node metastases had occurred in only one of the tumours with re-expression of p16 (Figure 6B). Mesenterial lymph nodes had not been invaded by metastatic cells in any of the mice (data not shown).

As lymphatic spread was the prevalent mode of metastasis in MiaPaca-2-TREx-p16 tumours, we compared the LVDs in tumours from mice with $(\mathrm{N}+)$ or without lymph node infiltration $(\mathrm{N}-)$ (Figure 6C). A significant difference in LVDs was observed between groups, suggesting that reduced lymphvascularisation in tumours with p16 expression had impaired their capacity for metastatic spread. In contrast, no difference was found with respect to hemangiogenesis as calculated from the difference of MVD and LVD (data not shown).

\section{DISCUSSION}

Functional inactivation of the tumour suppressor p16 marks a key event in pancreatic carcinogenesis. Conversely, reconstitution of the biological action of p16 provides an attractive therapeutic approach. Here, we addressed the consequences of p16 re-expression in MiaPaca-2 pancreatic cancer cells in vivo in the orthotopic tissue context. Consistent with previous work in subcutaneous xenograft models (Spillare et al, 1996; Harada et al, 1999; Hosotani et al, 2002), we found p16 capable of reducing primary tumour growth. In addition, p16 restitution resulted in a marked reduction of tumour angiogenesis, largely accounted for by a p16-dependent inhibition of lymphangiogenesis. In excellent agreement with the antilymphangiogenic effect, re-expression of 


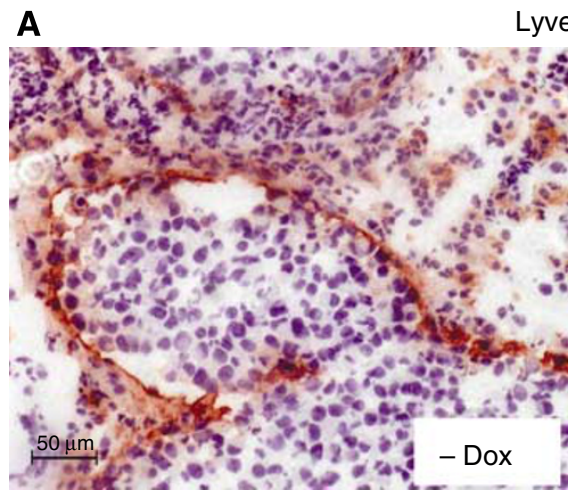

yve-1-IHC
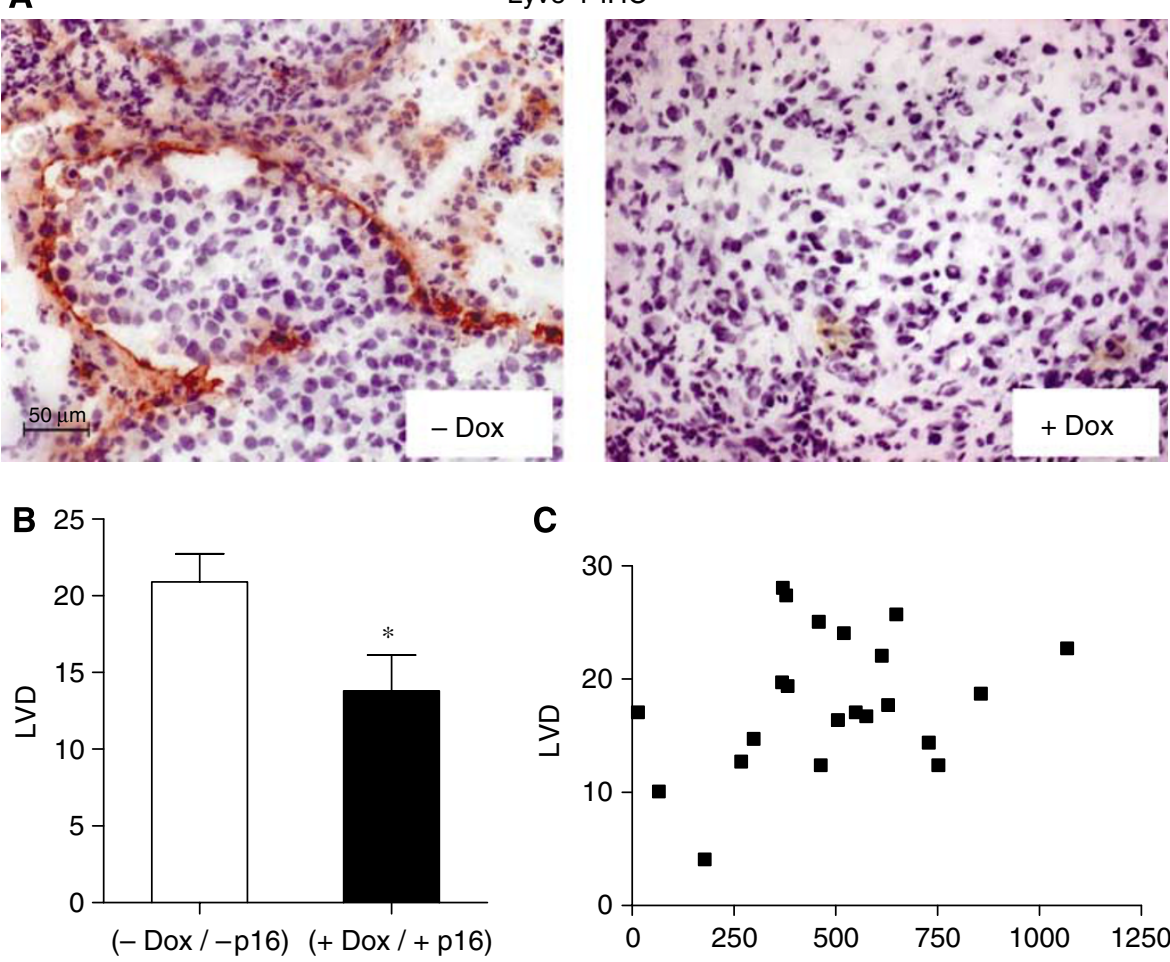

C

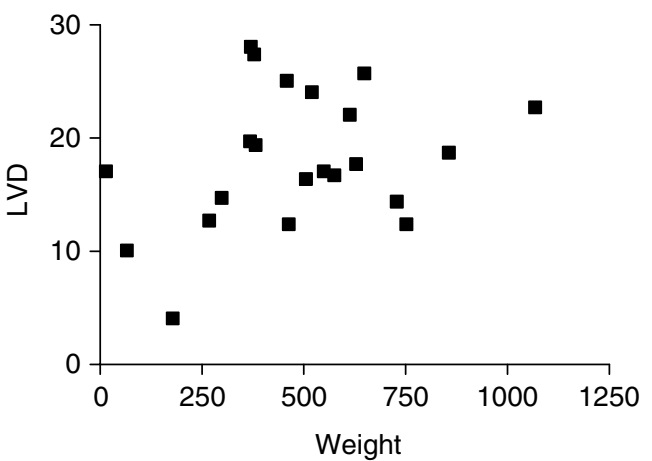

Figure 5 Induction of p 16 expression reduced lymphangiogenesis in orthotopic MiaPaCa-2 pancreatic carcinomas. Cryosections of the tumours were stained with Lyve-I, an endothelial cell marker, which specifically detects lymphatic endothelia. (A) Illustration of Lyve-I immunohistochemical detection in representative tumours from control (-Dox) and treatment group (+ Dox) (images at $\times 20$ magnification). (B) Quantitative evaluation of lymphatic vessel density $(\mathrm{LVD})$ for each group $(+/-\mathrm{Dox}) . * P<0.05$. (C) Missing correlation of LVD and tumour weight.

p16 prevented lymph node metastases of MiaPaca-2 pancreatic cancer cells. To our knowledge, this is the first report that experimentally links p16 to the process of lymphangiogenesis.

The restitution of p16 function remains an attractive therapeutic approach and a focus of drug development (Senderowicz and Sausville, 2000; Hosotani et al, 2002; Kondo et al, 2004).

So far, little is known about the consequences of p16 re-expression for more complex aspects of organ-specific tumour growth, which we focussed on in the current study. To this end, we combined a tetracycline-inducible expression system with an orthotopic approach, which allowed to overcome several potential obstacles.

The inducible system permitted selection, expansion, and continuous culture of stable clones, while avoiding the selection pressure expected from overexpression of a tumour suppressor. Upon addition of Dox, functionally relevant expression of p16 in MiaPaca-2-TREx-p16 was reproducibly obtained as judged from the ability to downmodulate pRB (Fang et al, 1998) and to reduce colony formation in soft agar (Plath et al, 2000), but did not block proliferation of MiaPaca-2 cells. Thus, the system seemed well suited for further in vivo use.

For several reasons, the orthotopic approach seemed of particular benefit: First, primary tumours were allowed to form and progress within their correct microenvironment. Thus, tissuespecific interactions between tumour cells and the stromal and vascular compartments, which are increasingly recognised as major determinants of the tumour phenotype, were maintained (Blouw et al, 2003; Chu et al, 2007). Second, orthotopic pancreatic tumours metastasised using the clinically relevant route of lymphatic metastasis and thereby offered information that is unavailable from subcutaneous xenografts. Third, the orthotopic approach in nude mice allowed to utilise human carcinoma cells, which are expected to reflect the characteristic molecular makeup of the human disease. Thus, the orthotopic model offers the potential to obtain clinically relevant data on the effects of p16 restitution in pancreatic cancer (Killion et al, 1998).

Although a successful combination of the inducible system with the orthotopic approach was feasible, almost one-third of the Doxtreated tumours did not express p16 at the time of autopsy. This may result from insufficient Dox delivery to the tumour cells or from selection pressure to inactivate the tumour suppressor. As these tumours may have been subjected to p16 expression for an uncertain period of time, they had to be omitted from most analyses. From the analyses of the remaining tumours with confirmed p16 expression, several insights were obtained.

MiaPaca-2-TREx-p16 cells formed well vascularised orthotopic primary tumours. This angiogenic phenotype was not correlated to tumour size, suggesting it represented a characteristic feature of the tumour biology of MiaPaca-2 pancreatic tumours. Dense vascularisation was also confirmed with respect to lymph endothelia, which have become a focus of research due to their role in lymphatic metastasis (Stacker et al, 2002). Induction of p16 in vivo profoundly affected the angiogenic phenotype of MiaPaca-2TREx-p16 tumours, resulting in decreased microvessel density and lymphatic vessel density.

The p16-mediated suppression of the angiogenic phenotype observed here is in excellent agreement with data obtained by inactivation of p16 in the MIN (Multiple Intestinal Neoplasia) mouse model of colon carcinogenesis (Gibson et al, 2003, 2005). Colonic tumours in MIN mice with additional p16 deletion revealed a strikingly increased vascularisation and slightly larger size as compared with p16-competent control animals. This effect was restricted to tumours in the large intestine, suggesting tissue-specific aspects in the regulation of angiogenesis by p16. 

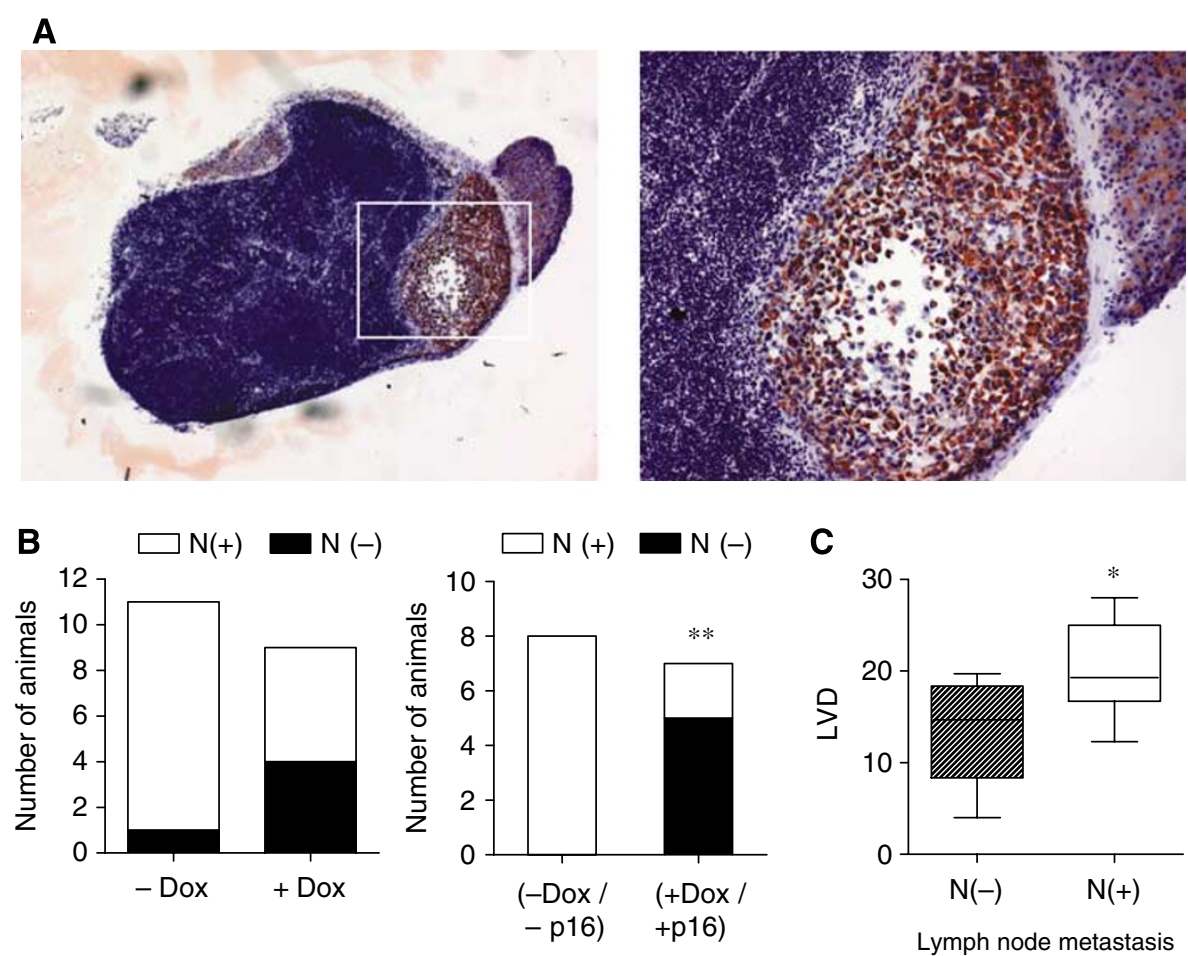

Figure 6 Induction of p 16 expression inhibits lymphatic spread of MiaPaCa-2 cells to the liver hilus lymph nodes. Metastatic spread of MiaPaCa-2-TRExp 16 cells was evaluated based on inspection of lung and abdominal organs at the time of autopsy and microscopic assessment of lymph node metastasis. (A) Representative picture of a lymph node with cytokeratin-positive human tumour cells (stained red) surrounded by lymphocytes (images at $\times 10$ magnification and $\times 20$ (image inset). (B) Quantitative analysis of lymph node metastasis. Data represent the number of animals with presence of lymph node metastasis in the liver hilus lymph nodes (left: comparison between treatment (+ Dox) and control group (-Dox). Right: subgroup analysis including only those animals with histologically confirmed expression or absence of pl6 protein (-Dox/pl6 vs +Dox/ + pl6) $(* * P<0.05)$ whereas in $(\mathbf{C})$ the correlation between LVD and lymph node metastasis is shown $(* P<0.05)$.

Such tissue specific effects possibly result from differences in the composition of proangiogenic factors from tumour cells, stromal cells and hypoxia (Craft and Harris, 1994). In this context, p16 was shown to suppress VEGF-A expression in vitro (Harada et al, 1999) and loss of p16 correlated with VEGF-A overexpression in human oesophageal squamous cell carcinoma specimens (Takeuchi et al, 2004). However, p16 induction in MiaPaca-2-TREx-p16 cells in vitro did not affect VEGF-A protein levels in cells or supernatants (data not shown), suggesting p16-controlled angiogenesis through alternate mechanisms.

One key contribution to the overall reduction of MVD was the marked decrease of lympahtic vessel density. This experimental link between p16 and lymphangiogenesis provides a pathobiological concept for earlier clinical observations that associated the loss of p16 with lymph node metastasis in several types of carcinomas (Kawabuchi et al, 1999; Gessner et al, 2002). Unfortunately, we could not examine this relationship in pancreatic cancer due to the scarcity of specimens with functionally intact p16.

Published work on lymphangiogenesis in pancreatic cancer has identified VEGF-C and VEGF-D as important stimulators (Tang et al, 2001; von Marschall et al, 2005) prompting us to test the effects of p16 induction on the amount of VEGF-C or -D produced in MiaPaca-2-TREx-p16 cells in vitro. However, neither of these two VEGF family members were found regulated, suggesting that additional factors controlled lymphangiogenesis in MiaPaca-2TREx-p16 tumours.

Irrespective of the mechanism whereby p16 reduced lymphangiogenesis our results strongly support the proposed sequence of p16 induction, reduction of lymphangiogenesis, and prevention of lymphatic metastasis in pancreatic cancer, as (i) p16 significantly inhibited lymph node metastasis, and (ii) mice with lymph node infiltration had significantly higher LVDs in their primary tumours. Given the importance of lymphatic metastasis for the clinical management of pancreatic cancer, our observations provide an important insight into the molecular events that determine this process. They furthermore suggest that p16 mimetic therapies provide benefits beyond the reduction of tumour cell proliferation and primary tumour burden.

\section{ACKNOWLEDGEMENTS}

We thank Jens Jeschke ${ }^{2}$ for his excellent technical assistance. PS was supported by a grant from DFG (Graduiertenkolleg 276/4 'Signalerkennung und -umsetzung'), BW and SR were supported by grants from Horst Müggenburg Stiftung, Deutsche Krebshilfe, DFG, Wilhelm-Sander Stiftung, Else Kröner Fresenius Stiftung, Berliner Krebsgesellschaft and Sonnenfeld-Stiftung. KD was supported by a grant from Wilhelm-Sander Stiftung.

\section{REFERENCES}

Aguirre AJ, Bardeesy N, Sinha M, Lopez L, Tuveson DA, Horner J, Redston MS, DePinho RA (2003) Activated K-ras and Ink4a/Arf deficiency cooperate to produce metastatic pancreatic ductal adenocarcinoma. Genes Dev 17: $3112-3126$ 
Ahmed SA, Gogal Jr RM, Walsh JE (1994) A new rapid and simple nonradioactive assay to monitor and determine the proliferation of lymphocytes: an alternative to [3H]thymidine incorporation assay. J Immunol Methods 170: 211-224

Alves F, Contag S, Missbach M, Kaspareit J, Nebendahl K, Borchers U, Heidrich B, Streich R, Hiddemann W (2001) An orthotopic model of ductal adenocarcinoma of the pancreas in severe combined immunodeficient mice representing all steps of the metastatic cascade. Pancreas 23: $227-235$

Bardeesy N, Aguirre AJ, Chu GC, Cheng KH, Lopez LV, Hezel AF, Feng B, Brennan C, Weissleder R, Mahmood U, Hanahan D, Redston MS, Chin L, DePinho RA (2006) Both p16(Ink4a) and the p19(Arf)-p53 pathway constrain progression of pancreatic adenocarcinoma in the mouse. Proc Natl Acad Sci USA 103: 5947-5952

Blouw B, Song H, Tihan T, Bosze J, Ferrara N, Gerber HP, Johnson RS, Bergers G (2003) The hypoxic response of tumors is dependent on their microenvironment. Cancer Cell 4: 133-146

Caldas C, Hahn SA, da Costa LT, Redston MS, Schutte M, Seymour AB, Weinstein CL, Hruban RH, Yeo CJ, Kern SE (1994) Frequent somatic mutations and homozygous deletions of the p16 (MTS1) gene in pancreatic adenocarcinoma. Nat Genet 8: 27-32

Chu GC, Kimmelman AC, Hezel AF, DePinho RA (2007) Stromal biology of pancreatic cancer. J Cell Biochem 101: 887-907

Craft PS, Harris AL (1994) Clinical prognostic-significance of tumor angiogenesis. Ann Oncol 5: 305-311

Fang X, Jin X, Xu HJ, Liu L, Peng HQ, Hogg D, Roth JA, Yu Y, Xu F, Bast Jr RC, Mills GB (1998) Expression of p16 induces transcriptional downregulation of the RB gene. Oncogene 16: 1-8

Gessner C, Liebers U, Kuhn H, Stiehl P, Witt C, Schauer J, Wolff G (2002) BAX and p16INK4A are independent positive prognostic markers for advanced tumour stage of nonsmall cell lung cancer. Eur Respir J 19: $134-140$

Gibson SL, Boquoi A, Chen T, Sharpless NE, Brensinger C, Enders GH (2005) p16(Ink4a) inhibits histologic progression and angiogenic signaling in min colon tumors. Cancer Biol Ther 4: 1389-1394

Gibson SL, Dai CY, Lee HW, DePinho RA, Gee MS, Lee WM, Furth EE, Brensinger C, Enders GH (2003) Inhibition of colon tumor progression and angiogenesis by the Ink4a/Arf locus. Cancer Res 63: 742-746

Gossen M, Freundlieb S, Bender G, Muller G, Hillen W, Bujard H (1995) Transcriptional activation by tetracyclines in mammalian cells. Science 268: 1766 - 1769

Harada H, Nakagawa K, Iwata S, Saito M, Kumon Y, Sakaki S, Sato K, Hamada K (1999) Restoration of wild-type p16 down-regulates vascular endothelial growth factor expression and inhibits angiogenesis in human gliomas. Cancer Res 59: 3783-3789

Hezel AF, Kimmelman AC, Stanger BZ, Bardeesy N, DePinho RA (2006) Genetics and biology of pancreatic ductal adenocarcinoma. Genes Dev 20: $1218-1249$

Hosotani R, Miyamoto Y, Fujimoto K, Doi R, Otaka A, Fujii N, Imamura M (2002) Trojan p16 peptide suppresses pancreatic cancer growth and prolongs survival in mice. Clin Cancer Res 8: 1271-1276

Kawabuchi B, Moriyama S, Hironaka M, Fujii T, Koike M, Moriyama H, Nishimura Y, Mizuno S, Fukayama M (1999) p16 inactivation in small-sized lung adenocarcinoma: its association with poor prognosis. Int J Cancer 84: $49-53$

Killion JJ, Radinsky R, Fidler IJ (1998) Orthotopic models are necessary to predict therapy of transplantable tumors in mice. Cancer Metastasis Rev 17: $279-284$

Kim WY, Sharpless NE (2006) The regulation of INK4/ARF in cancer and aging. Cell 127: $265-275$
Kondo E, Seto M, Yoshikawa K, Yoshino T (2004) Highly efficient delivery of p16 antitumor peptide into aggressive leukemia/lymphoma cells using a novel transporter system. Mol Cancer Ther 3: $1623-1630$

Maurelli R, Zambruno G, Guerra L, Abbruzzese C, Dimri G, Gellini M, Bondanza S, Dellambra E (2006) Inactivation of p16INK4a (inhibitor of cyclin-dependent kinase $4 \mathrm{~A}$ ) immortalizes primary human keratinocytes by maintaining cells in the stem cell compartment. FASEB J 20: 1516-1518

Nakayama GR, Caton MC, Nova MP, Parandoosh Z (1997) Assessment of the Alamar Blue assay for cellular growth and viability in vitro. J Immunol Methods 204: 205-208

Plath T, Detjen K, Welzel M, von Marschall Z, Murphy D, Schirner M, Wiedenmann B, Rosewicz S (2000) A novel function for the tumor suppressor p16(INK4a): induction of anoikis via upregulation of the alpha(5)beta(1) fibronectin receptor. J Cell Biol 150: 1467-1478

Rocco JW, Li D, Liggett Jr WH, Duan L, Saunders Jr JK, Sidransky D, O’Malley Jr BW (1998) p16INK4A adenovirus-mediated gene therapy for human head and neck squamous cell cancer. Clin Cancer Res 4: $1697-1704$

Rocco JW, Sidransky D (2001) p16(MTS-1/CDKN2/INK4a) in cancer progression. Exp Cell Res 264: 42-55

Rozenblum E, Schutte M, Goggins M, Hahn SA, Panzer S, Zahurak M, Goodman SN, Sohn TA, Hruban RH, Yeo CJ, Kern SE (1997) Tumorsuppressive pathways in pancreatic carcinoma. Cancer Res 57: 1731 - 1734

Senderowicz AM, Sausville EA (2000) Preclinical and clinical development of cyclin-dependent kinase modulators. J Natl Cancer Inst 92: 376-387

Serrano M, Hannon GJ, Beach D (1993) A new regulatory motif in cell-cycle control causing specific inhibition of cyclin D/CDK4. Nature 366: $704-707$

Spillare EA, Okamoto A, Hagiwara K, Demetrick DJ, Serrano M, Beach D, Harris CC (1996) Suppression of growth in vitro and tumorigenicity in vivo of human carcinoma cell lines by transfected p16(INK4). Mol Carcinog 16: 53-60

Stacker SA, Achen MG, Jussila L, Baldwin ME, Alitalo K (2002) Lymphangiogenesis and cancer metastasis. Nat Rev Cancer 2: 573-583

Takeuchi H, Ozawa S, Shih CH, Ando N, Kitagawa Y, Ueda M, Kitajima M (2004) Loss of p16INK4a expression is associated with vascular endothelial growth factor expression in squamous cell carcinoma of the esophagus. Int J Cancer 109: 483-490

Tang RF, Itakura J, Aikawa T, Matsuda K, Fujii H, Korc M, Matsumoto Y (2001) Overexpression of lymphangiogenic growth factor VEGF-C in human pancreatic cancer. Pancreas 22: 285-292

von Marschall Z, Scholz A, Stacker SA, Achen MG, Jackson DG, Alves F, Schirner M, Haberey M, Thierauch KH, Wiedenmann B, Rosewicz S (2005) Vascular endothelial growth factor-D induces lymphangiogenesis and lymphatic metastasis in models of ductal pancreatic cancer. Int J Oncol 27: 669-679

Wagner M, Greten FR, Weber CK, Koschnick S, Mattfeldt T, Deppert W, Kern H, Adler G, Schmid RM (2001) A murine tumor progression model for pancreatic cancer recapitulating the genetic alterations of the human disease. Genes Dev 15: 286-293

Weidner N (1995) Current pathologic methods for measuring intratumoral microvessel density within breast carcinoma and other solid tumors. Breast Cancer Res Treat 36: 169-180

Xiong HQ, Carr K, Abbruzzese JL (2006) Cytotoxic chemotherapy for pancreatic cancer: advances to date and future directions. Drugs 66: $1059-1072$

Yao F, Svensjo T, Winkler T, Lu M, Eriksson C, Eriksson E (1998) Tetracycline repressor, tetR, rather than the tetR-mammalian cell transcription factor fusion derivatives, regulates inducible gene expression in mammalian cells. Hum Gene Ther 9: 1939-1950 